\title{
Do the home field, global advantage, and liability of unfamiliarness hypotheses hold? Empirical evidence from Malaysia
}

\begin{abstract}
The study explores the home field, global advantage, and liability of unfamiliarness hypotheses in the Malaysian banking sector. The results indicate that Malaysian banks have exhibited productivity progress mainly attributed to technological progress. The authors find negative relationship between foreign and government ownership and bank productivity. Likewise, the publicly listed banks have been relatively less productive compared to private banks, thus rejecting the market discipline hypothesis. The empirical findings suggest that foreign banks from the North American countries to be the least productive banking group lending support to the home field advantage and the limited form of the global advantage hypotheses.
\end{abstract}

Keyword: Bank; Bootstrap malmquist productivity index; Bootstrap regression analysis; Malaysia; Total factor productivity 